\title{
A longitudinal study of iron status in children at 12,24 and 36 months
}

\author{
VE Freeman ${ }^{1, *}, \mathrm{~J} \mathrm{Mulder}^{3}$, MA van't Hof ${ }^{3}, \mathrm{HMV} \mathrm{Hoey}^{2}$ and M Gibney ${ }^{1}$ \\ 'Division of Nutritional Sciences, Department of Clinical Medicine, Trinity Centre for Health Sciences, \\ St James's Hospital, Dublin 8, Ireland: '2Department of Paediatrics, the University of Dublin, Trinity \\ College, Dublin 2, Ireland: ${ }^{3}$ Department of Medical Statistics, Catholic University of Nijmegen, \\ Nijmegen, The Netherlands
}

Submitted 8 December 1997: Accepted 8 April 1998

\begin{abstract}
Objectives: To assess iron status in a sample of clinically well, Caucasian children and explore the complex factors which contribute to iron deficiency during infancy.

Design: Infants recruited at birth and followed longitudinally at 1, 2, 3, 4, 5, 6, 9, 12, 24 and 36 months; feeding practices and socioeconomic data recorded. Iron status assessed using venous blood at 12, 24 and 36 months.

Setting: Baseline data recorded in the maternity unit. Follow-up visits took place in the infants' homes and blood sampling in a paediatric hospital.

Subjects: Subjects comprised a mixed socioeconomic group of healthy children $(n=121)$. Blood samples taken from 85,72 and $67 \%$ at 12,24 and 36 months, respectively.

Results: Prevalence of anaemia $\left(\mathrm{Hb}<110 \mathrm{gl}^{-1}\right)$ in the longitudinal sample $(n=76)$ increased from $2.6 \%$ at age 12 months to $9.2 \%$ at 24 months, and at age 36 months $(n=70)$ was $8 \%$. The most significant finding was that at age 12 months, cows' milk consumption was negatively associated with iron status. Other variables also had an influence. At both 24 and 36 months the most significant predictor of iron status was earlier iron status.

Conclusions: Infants born to anaemic mothers or mothers who smoke and infants who consume cows' milk during infancy are at increased risk of developing anaemia. Breast milk is the ideal, but for the infant who is not breast fed an iron fortified formula should be used. Advice to mothers should focus on the importance of introducing nutrient dense complementary foods, such as meat, which contains readily absorbable iron.
\end{abstract}

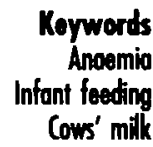

Iron deficiency anaemia of infancy has declined in many countries as a result of improved feeding practices but the condition remains relatively common ${ }^{1}$. The UK National Diet and Nutrition Survey $^{2}$ (NDNS) provides cross-sectional data on the iron status of a sample of over 900 children, aged 1.54.5 years, of whom two-thirds were aged $1.5-3.5$ years. In the sample as a whole, $8 \%$ were found to have haemoglobin $(\mathrm{Hb})<110 \mathrm{gl}^{-1}$; this included $12 \%$ of the $1.5-2.5$ year olds and $6 \%$ of those aged $2.5-3.5$ years. Twenty-three per cent of 8-month-old Avon infants had $\mathrm{Hb}<110 \mathrm{gl}^{-1}$ in another UK study ${ }^{3}$.

Increasing evidence suggests that even mild iron deficiency anaemia of greater than 3 months duration can have a long-term detrimental influence on mental and psychomotor development, making the prevention and early treatment of iron deficiency a priority for paediatric health care ${ }^{4-6}$. The factors which predispose to the development of iron deficiency and anaemia, together with the prevalence of the disorder, need to be clearly understood before effective preventative measures can be initiated.

Available studies give much information about the prevalence of anaemia in various paediatric populations but many include hospitalized patients, in whom anaemia may be disease related ${ }^{7,8}$, or subjects from disadvantaged communities ${ }^{9,10}$ and ethnic minority groups $^{11,12}$, who are at increased risk of developing anaemia. Others provide only cross-sectional data, which give no information about the changes which take place in iron status over time ${ }^{2,3}$. In reality, the supply of, and demand for, iron form part of a constantly balancing cycle and iron deficiency develops after a prolonged period of either inadequate supply, increased demand or a combination of the two. Infants have a high requirement for iron as a result of their rapid growth rates.

The influence of milk feeding practices on iron 
supply has been examined in certain subgroups ${ }^{10,12}$ but feeding data are often collected retrospectively or at the same time as blood samples ${ }^{11}$ whereas earlier feeding practices will have a distinct influence on current iron status. A more comprehensive range of factors which might affect the supply of iron is not usually considered. To our knowledge, no longitudinal studies have reported on factors influencing iron status of a mixed socioeconomic group of community-based children from birth to age 3 years.

This study assesses the prevalence of iron deficiency and iron deficiency anaemia in a longitudinal sample of normal, clinically well, infants at the ages of 12,24 and 36 months. Nutritional, social and environmental data were recorded prospectively from birth. Relationships between iron status and these variables are examined.

\section{Subjects and methods}

The protocol was approved by the ethics committee of the Federated Dublin Voluntary Hospitals. A sample of 121 consecutive, normal, healthy infants was recruited at birth from the Coombe Women's Hospital, Dublin, one of three major maternity units in the city, with approximately 7000 births per annum. Infants were excluded if the mother had diabetes, epilepsy or any condition which required her to take medication on a regular basis, if birth weight was $<2500 \mathrm{~g}$, gestational age $<37$ weeks or unknown or if the infant had any congenital malformations, chronic or inherited metabolic disease, or any illness that required hospitalization for more than 7 days. Pregnancies resulting from non-natural insemination were excluded as were those infants whose fathers were unknown. Only singleton infants were included in the sample, which included those from public $(60 \%)$, private $(30 \%)$ and semi-private (10\%) wards. During the recruitment period 31 mothers refused to participate. Baseline characteristics were recorded for these mother-infant pairs.

In the immediate postnatal period birth weight, length, head circumference, choice of feeding method and socioeconomic data were recorded. Maternal $\mathrm{Hb}$ concentration during pregnancy was taken from hospital records. Usually only one Hb measurement, recorded at the booking visit, was available. If the $\mathrm{Hb}$ measurement was repeated, the lower of the values was used. Follow-up visits were organized in the infants' homes, monthly for the first 6 months and at the ages of $9,12,18,24,30$ and 36 months. At each visit anthropometric measurements were taken and a questionnaire, which recorded the type of milk feeding used, the frequency of feeding, the volume of formula or cows' milk consumed, the age of weaning to solid foods and the various foods used, was completed by one investigator. Type of milk feeding was categorized as either breast feeding (exclusive or partial), infant formula (all available infant formula is iron fortified), follow-on formula or cows' milk. The age of introduction of cows' milk was derived from the longitudinal data. The quantity of milk consumed daily was the usual daily intake as reported by the carer, who was generally the mother. The mother was asked whether the child was feeding from a bottle or a cup or both. The number of drinks taken daily from a bottle and the volume of each and the number of drinks taken from a cup and the volume of each were recorded. The quantity of cows' milk consumed during the first year of life was calculated from usual daily consumption, which was recorded at the ages of $1,2,3$, 4, 5, 6, 9 and 12 months. If the infant had been transferred from one milk to another in the interim period between visits the calculation took account of this. At the ages of 12, 24 and 36 months venous blood samples were taken from $92(85 \%), 78(72 \%)$ and 70 (67\%) infants, respectively. The longitudinal samples comprised 76 infants (12-24 months) and 70 infants (24-36 months).

Analyses for haemoglobin (Hb), haematocrit (Hct), mean corpuscular volume (MCV), mean corpuscular $\mathrm{Hb}(\mathrm{MCH})$, mean corpuscular $\mathrm{Hb}$ concentration (MCHC) and red cell distribution width (RDW) were completed using Coulter counter (model STKS). Serum was analysed for serum ferritin (SF) by radioimmunoassay (FER-CTRIA, CIS Bio International, France); total iron binding capacity (TIBC) calculated from transferrin using immunodiffusion (NORPartigen, Behring) and serum iron (Kodak Ektachem clinical chemistry slide).

Differences between mean values for haematological variables measured at the ages of 12,24 and 36 months were assessed using paired student's $t$-tests. Multivariate regression analysis was performed to explain iron status from other variables. At age 12 months, independent variables included in the regression were gestational age, birth weight, sex, level of education of the mother, smoking habits of the mother during pregnancy, milk feeding method and the quantity of cows' milk consumed during the first year of life, the age of introduction of meat, the infant's use of supplemental iron and markers of maternal iron status. At the ages of 24 and 36 months, markers of earlier iron status of the infant were included in the regression model as independent variables. Dependent variables examined were $\mathrm{Hb}, \mathrm{MCV}$ and $\mathrm{SF}$.

\section{Results}

There were no significant differences between participants and non-participants for birth weight, maternal age, maternal height or the percentage of urban or rural families included. A trend for participating mothers 
Table 1 Characteristics of the longitudinal sample at 12 and 24 months $(n=76)$ and of remaining infants $(n=45)$. Mean values are given with standard deviations in parentheses

\begin{tabular}{lcc}
\hline & $\begin{array}{c}\text { Longitudinal sample } \\
(n=76)\end{array}$ & $\begin{array}{c}\text { Remaining infants } \\
(n=45)\end{array}$ \\
\hline Birth weight (g) & $3573(425)$ & $3654(457)$ \\
Birth length (cm) & $50.8(1.7)$ & $52.4(2.1)$ \\
Age of mothers (years) & $29(5)$ & $29(5)$ \\
Age of fathers (years) & $31(6)$ & $28(6)$ \\
Age mothers' education stopped (years) & $17(4)$ & $17(4)$ \\
Age fathers' education stopped (years) & $17(6)$ & $14(8)$ \\
$\%$ Boys & 55 & 43 \\
\% Families with both parents unemployed & 14.5 & 15.8 \\
$\%$ Families with neither parent unemployed & 48.7 & 30.7 \\
\% Families with no central heating & 22.0 & 32.8 \\
\% Mothers who took medicinal iron during pregnancy & 76 & 65 \\
\hline
\end{tabular}

to have a higher level of education did not reach statistical significance.

Mothers who were willing to allow blood samples to be taken from their children comprised 85,72 and $67 \%$ of participants at the ages of 12,24 and 36 months, respectively. Table 1 summarizes the characteristics of those who were included in the longitudinal sample at 12 and 24 months $(n=76)$ and of those who were not $(n=45)$. Milk feeding practices of those included in the longitudinal sample at 12 and 24 months $(n=76)$ are shown in Fig. 1. Formula milks were far the most popular up to age 9 months but cows' milk was commonly used at age 12 months. Infants were being fed cows' milk from as early as 2 months, $9 \%$ receiving cows' milk by age 4 months. Table 2 shows mean volumes of cows' milk $\left(\mathrm{ml} \mathrm{day}^{-1}\right)$ being consumed during the first year. The percentage of infants who were breast fed was low, falling from $25 \%$ at 1 month to $11 \%$ at 6 months and $6 \%$ at 12 months. Commercially produced, iron fortified infant cereals were most frequently used as first weaning foods. By age 12 months, about $85 \%$ of infants were eating meat, fish or chicken daily. Most others consumed meat, fish or chicken on a regular, but less frequent, basis. No vegetarian children were included.

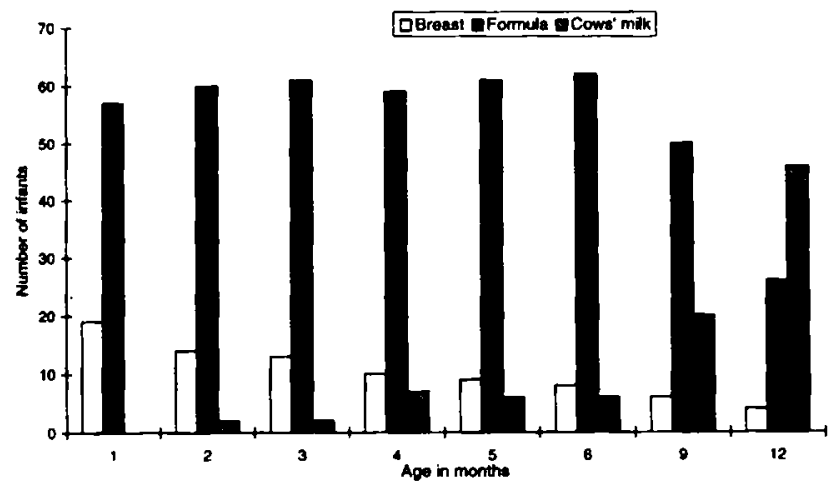

Fig. 1 Milk feeding during the first year of life in the longitudinal sample $(n=76)$
At age 12 months, mean $\mathrm{Hb}$ in the total sample was $122.5 \mathrm{gl}^{-1}$ (SD 7.9). Of the 92 infants, three (3.2\%) had $\mathrm{Hb}<110 \mathrm{gl}^{-1}$. For one infant $\left(\mathrm{Hb} 109 \mathrm{gl}^{-1}\right.$ ), all other haematological parameters were within the appropriate reference ranges. The other two showed further haematological evidence of iron deficiency (SF $<1$ and $3 \mu \mathrm{gl}^{-1}$; TIBC 525 and $574 \mu \mathrm{g} \mathrm{dl}^{-1}$ ), had been introduced to cows' milk from the age of 2 months and had inadequate intakes of heme iron. Meat, fish or chicken was being eaten by them during only two of the eight interview periods during the first year of life, by one child at ages 4 and 5 months and by the other, irregularly at age 9 months, and at age 12 months. Mothers of both infants who were anaemic at age 12 months had been severely anaemic ( $\mathrm{Hb}<85 \mathrm{gl}^{-1}$ ) during their pregnancies. The mean $\mathrm{Hb}$ in those mothers for whom data was available $(n=51)$ was $116 \mathrm{gl}^{-1}$ and no other mother recorded a $\mathrm{Hb}<90 \mathrm{gl}^{-1}$.

Mean (SD) for a range of haematological variables in the longitudinal samples at ages 12, 24 and 36 months are presented in Tables 3 and 4 . By age 24 months mean $\mathrm{Hb}$ had fallen slightly to $120.2 \mathrm{gl}^{-1}$, but this decrease was not statistically significant, and seven infants $(9.2 \%)$ had $\mathrm{Hb}<110 \mathrm{gl}^{-1}$. All seven had $\mathrm{SF}$ $<10 \mu \mathrm{gl}^{-1}$. Mean $\mathrm{Hb}$ at age 36 months was $120 \mathrm{gl}^{-1}$ and $8 \%$ had $\mathrm{Hb}<110 \mathrm{gl}^{-1}$. Together with this fall in the percentage found to be anaemic, mean MCV, RDW and TIBC showed significant improvement during the third year (Table 4).

Table 2 Cows' milk consumption $\left(\mathrm{ml} \mathrm{day}^{-1}\right)$ during the first year of life ( $n$ max. $=92$ )

\begin{tabular}{lccccc}
\hline Age (months) & $n$ & Mean & SD & Minimum & Maximum \\
\hline 1 & 0 & - & - & - & - \\
2 & 2 & 881 & 40 & 852 & 909 \\
3 & 2 & 853 & 241 & 682 & 1023 \\
4 & 7 & 763 & 268 & 426 & 1136 \\
5 & 6 & 885 & 239 & 540 & 1136 \\
6 & 6 & 838 & 285 & 398 & 1136 \\
9 & 26 & 580 & 284 & 114 & 1023 \\
12 & 63 & 524 & 242 & 21 & 1193 \\
\hline
\end{tabular}


Table 3 Mean (SD) of haematological variables in the longitudinal sample $(n=76)$ at ages 12 and 24 months

\begin{tabular}{lccccccc}
\hline & $H b\left(\mathrm{gl}^{-1}\right)$ & S. ferritin $\left(\mu \mathrm{gl}^{-1}\right)$ & Hct ratio & MCV (fl) & RDW & TIBC $\left(\mu \mathrm{gdH^{-1 } )}\right.$ & Ts\% \\
\hline 12 months & 121.9 & 16.8 & 0.357 & 77.1 & 13.8 & 398 & 23 \\
& $(7.7)$ & $(12.2)$ & $(0.023)$ & $(3.8)$ & $(1.2)$ & $(53)$ & $(17)$ \\
24 months & 120.1 & 10.1 & 0.352 & 76.4 & 14.0 & 409 & $(19)$ \\
& $(9.0)$ & $(5.8)$ & $(0.023)$ & $(5.6)$ & $(1.5)$ & $(11)$ \\
$P$ & NS & $<0.0001$ & NS & NS & NS & NS & NS \\
\hline
\end{tabular}

$\mathrm{Hb}=$ haemoglobin; $\mathrm{S}$. ferritin = serum ferritin; $\mathrm{Hct}=$ haematocrit; $\mathrm{MCV}=$ mean corpuscular volume; RDW = red cell distribution width; TIBC = total iron binding capacity; Ts\% = percentage saturation of transferrin; $P=$ difference between 12-month and 24-month values.

Mean SF was $17.5 \mu \mathrm{g}^{-1}$ (SD 12.3) at age 12 months. Twenty-three per cent of the total and $8 \%$ of those fed iron fortified formula throughout the first year appeared iron deficient $\left(\mathrm{SF}<10 \mu \mathrm{gl}^{-1}\right)$. However, the lower limit of the normal reference range for $\mathrm{SF}$ is poorly defined in infant populations. The distribution of ferritin in infants is positively skewed, as it is in adults ${ }^{13}$, so a small shift in the lower limit would result in a considerable number of infants being categorized differently. In this case $43 \%$ of infants who had SF $<10 \mu \mathrm{gl}^{-1}$ would not have been categorized as iron deficient if the lower reference limit was $7 \mu \mathrm{gl}^{-1}$. The maximum ferritin value fell from $61 \mu \mathrm{gl} \mathrm{l}^{-1}$ to $26 \mu \mathrm{g} 1^{-1}$ between the ages of 12 and 24 months. In the longitudinal sample $(n=76)$ mean SF fell from $16.8 \mu \mathrm{gl}^{-1}$ at age 12 months to $10.1 \mu \mathrm{gl}^{-1}$ at age 24 months and this decrease was statistically significant $(P<0.0001)$ (see Table 3 ). At age 2 years, 38 infants $(50 \%)$ had SF $<10 \mu \mathrm{gl}^{-1}$ and $24(31 \%)$ had SF $<7 \mu \mathrm{gl}^{-1}$. In the 3-year-old children mean SF was $12.3 \mu \mathrm{gl}^{-1}$ (SD 9.2); $46 \%$ had $\mathrm{SF}<10 \mu \mathrm{gl}^{-1}$ and $26 \%<7 \mu \mathrm{gl}^{-1}$. In the $8 \%$ who were anaemic at age 36 months, mean SF was $8.8 \mu \mathrm{gl}^{-1}$ (range $1-21 \mu \mathrm{gl}^{-1}$ ). Correlations were found between $\mathrm{Hb}$ and SF at both 12 and 24 months but not at 36 months $(r=0.26, P=0.023$ at age 12 months and $r=0.66, P=0.000$ at 24 months).

Multivariate regression analysis (Table 5) showed that the quantity of cows' milk consumed during the first year was negatively associated with $\mathrm{Hb}(r=-0.36$; $P<0.000)$, MCV $(r=-0.42 ; \quad P<0.026)$ and $\mathrm{SF}$ $(r=-0.42 ; P<0.001)$. If the age of introduction, rather than the quantity, of cows' milk was used in the regression model a similar, significant, but less strong association was found. Haematological variables recorded at 12 and 24 months were included in the regression model to explain later iron status and each dependent variable was found to be significantly influenced by its value 12 months earlier. Smoking during pregnancy negatively influenced iron status indicators at the ages 12 and 24 months. The possible confounding effect of other socioeconomic variables on this association was examined, but none was found to be significant.

At age 12 months all breast fed infants had $\mathrm{Hb}$ $>115 \mathrm{gl}^{-1}$ and $\mathrm{SF}$ ranged from 5 to $12 \mu \mathrm{gl}^{-1}$; three of the five infants had SF $<10 \mu \mathrm{gl}^{-1}\left(5,8\right.$ and $\left.9 \mu \mathrm{gl}^{-1}\right)$. All three were eating meat, fish or chicken daily. Although breast feeding was associated with 'low' SF, the relationship was weak and there was a significant correlation between breast feeding and later introduction of solids, excluding meat and fruit $(r=0.46$, $P=0.000$ ). Low $\mathrm{SF}$ is taken to be synonymous with poor iron status, but no further evidence to support this view can be seen in the breast fed baby with the lowest SF level. The full haematological profile of this infant was as follows: SF $5 \mu \mathrm{gl}^{-1} ; \mathrm{Hb}^{12} \mathrm{~g} \mathrm{dl}^{-1}$; HCt ratio 0.344; MCV $75.9 \mathrm{fl}$; $\mathrm{MCH} 26.5 \mathrm{pg}$; MCHC $34.9 \mathrm{~g} \mathrm{dl}^{-1}$; RDW 13.4; TIBC $423 \mu \mathrm{g} \mathrm{dl}^{-1}$; Ts $16 \%$.

\section{Discussion}

Mean $\mathrm{Hb}\left(122 \mathrm{~g} \mathrm{l}^{-1}\right)$ in this sample at age 12 months compares favourably with that recorded by Burman who found a mean of $117.5 \mathrm{gl}^{-1}$ (SD 10.8) in a sample of 105 1-year-old infants who had been given no medicinal iron ${ }^{14}$ and is the same as the median value reported from the white $1-2$ year olds $(n=98)$ who were included in the Second National Health and

Table 4 Mean (SD) of haematological variables in the longitudinal sample $(n=70)$ at ages 24 and 36 months

\begin{tabular}{lccccccc}
\hline & $\mathrm{Hb}\left(\mathrm{g}^{-1}\right)$ & S. ferritin $\left(\mu \mathrm{gl}^{-1}\right)$ & Hct ratio & MCV (fl) & RDW & ${\text { TIBC }\left(\left.\mu \mathrm{gdl}\right|^{-1}\right)}^{\text {Ts\% }}$ \\
\hline 24 months & 120.0 & 9.9 & 0.352 & 76.4 & 14.1 & 409 & 18.7 \\
& $(0.92)$ & $(5.8)$ & $(0.023)$ & $(5.6)$ & $(1.5)$ & $(59)$ & $(11.2)$ \\
36 months & 120.0 & 12.3 & 0.349 & 78.3 & 13.5 & 377 & 19.8 \\
& $(0.8)$ & $(9.2)$ & $(0.021)$ & $(5.0)$ & $(1.3)$ & $(55)$ & $(11.4)$ \\
$P$ & NS & NS & NS & 0.03 & 0.01 & 0.001 & NS
\end{tabular}

$\mathrm{Hb}=$ haemoglobin; $\mathrm{S}$. ferritin = serum ferritin; $\mathrm{Hct}=$ haematocrit; $\mathrm{MCV}=$ mean corpuscular volume; RDW = red cell distribution width; TIBC = total iron binding capacity; Ts\% = percentage saturation of transferrin; $P=$ differences between 12-month and 24-month values. 
Table 5 Regression analyses: iron status at the ages of $12(n=92), 24(n=76)$ and $36(n=70)$ months

\begin{tabular}{|c|c|c|c|c|}
\hline Dependent variable & Independent variable§ & $r$ & $P$ & Adjusted $r^{2}$ \\
\hline $\begin{array}{l}\text { Age } 12 \text { months } \\
\mathrm{Hb}\end{array}$ & $\begin{array}{l}\text { Cows' milk } \\
\text { Iron supplement } \\
\text { Gestational age }\end{array}$ & $\begin{array}{r}-0.36 \\
0.21 \\
-0.27\end{array}$ & $\begin{array}{l}0.000 \\
0.001 \\
0.034\end{array}$ & 0.206 \\
\hline MCV & $\begin{array}{l}\text { Cows' milk* } \\
\text { Maternal MCV } \\
\text { Smoking DP† } \\
\text { Follow-up milk }\end{array}$ & $\begin{array}{r}-0.42 \\
0.30 \\
-0.40 \\
0.19\end{array}$ & $\begin{array}{l}0.026 \\
0.001 \\
0.002 \\
0.038\end{array}$ & 0.337 \\
\hline Log ferritin & $\begin{array}{l}\text { Cows' milk* } \\
\text { Smoking DPt } \\
\text { Breast feeding }\end{array}$ & $\begin{array}{l}-0.42 \\
-0.40 \\
-0.11\end{array}$ & $\begin{array}{l}0.001 \\
0.009 \\
0.041\end{array}$ & 0.264 \\
\hline $\begin{array}{l}\text { Age } 24 \text { months } \\
\mathrm{Hb}\end{array}$ & $\begin{array}{l}\text { Hb 1f } \\
\text { Log ferritin } 1 \\
\text { Smoking DPf }\end{array}$ & $\begin{array}{r}0.50 \\
0.53 \\
-0.44\end{array}$ & $\begin{array}{l}0.001 \\
0.005 \\
0.027\end{array}$ & 0.372 \\
\hline MCV & $\begin{array}{l}\text { MCV 1f } \\
\log \text { ferritin } 1\end{array}$ & $\begin{array}{l}0.73 \\
0.54\end{array}$ & $\begin{array}{l}0.000 \\
0.021\end{array}$ & 0.558 \\
\hline Log ferritin & $\begin{array}{l}\text { Cows' milk } \\
\text { Log ferritin } 1\end{array}$ & $\begin{array}{r}-0.53 \\
0.50\end{array}$ & $\begin{array}{l}0.000 \\
0.022\end{array}$ & 0.310 \\
\hline $\begin{array}{l}\text { Age } 36 \text { months } \\
\mathrm{Hb}\end{array}$ & $\begin{array}{l}\mathrm{Hb} 1 \\
\mathrm{Hb} 2 \ddagger\end{array}$ & $\begin{array}{l}0.59 \\
0.78\end{array}$ & $\begin{array}{l}0.002 \\
0.000\end{array}$ & 0.657 \\
\hline $\mathrm{MCV}$ & MCV 2 & 0.89 & 0.000 & 0.791 \\
\hline Log ferritin & $\begin{array}{l}\log \text { ferritin } 2 \\
\mathrm{Hb} 2\end{array}$ & $\begin{array}{l}0.55 \\
0.47\end{array}$ & $\begin{array}{l}0.000 \\
0.015\end{array}$ & 0.337 \\
\hline
\end{tabular}

Nutrition Examination Survey ${ }^{15}$. Burman emphasized the major physiological changes which occur in $\mathrm{Hb}$ levels during the first 12 months of life with a standardized range ( \pm 2 SD) from 96 to $143 \mathrm{gl}^{-1}$, and highlighted the persistent haemodynamic state which exists during infancy ${ }^{16}$. A UK study of 8-month-old infants found a mean $\mathrm{Hb}$ of $117 \mathrm{gl}^{-1}$, somewhat lower than in the 12-month-old Irish children ${ }^{3}$. In the NDNS ${ }^{2}$ mean $\mathrm{Hb}$ in the 1.5-2.5 and 2.5-3.5 year old children were $120 \mathrm{gl}^{-1}$ and $122 \mathrm{gl}^{-1}$, respectively, similar to values in the present groups.

The prevalence of anaemia (2.6\%) in this sample of apparently normal, clinically well infants at age 12 months is significantly lower than that reported in UK studies $^{7,11,12}$, increases to $9.2 \%$ during the second year of life and decreases again to $8 \%$ in the third year. Duggan et al. similarly found that the highest prevalence of anaemia was between 21 and 24 months ${ }^{11}$. The earlier UK studies included sample populations which differ from the present mixed socioeconomic group of Caucasian children. Results can more appropriately be compared with the NDNS ${ }^{2}$ in which $12 \%$ of those aged $1.5-2.5$ years, $6 \%$ of $2.5-3.5$ year olds and $8 \%$ of all children aged $1.5-4.5$ years had $\mathrm{Hb}<110 \mathrm{gl}^{-1}$. NDNS subjects were a representative sample selected from private households in England, Scotland and Wales. Blood samples were taken from $54 \%$ of the responding sample. Because the age groups are not matched with those in the present study, and in the knowledge that there are major physiological changes in iron status during infancy and early childhood, it is not possible to make precise comparisons between the groups. However, both studies were carried out during the same time period and it appears that a similar level of anaemia exists in the two populations at the age of 24 months. Improved iron status is also seen in both populations during the third year. The somewhat higher prevalence of anaemia in the UK children aged 1.5-2.5 years may be the result of inclusion in the sample of non-Caucasian subjects, with feeding patterns which differ from the Caucasian population. This possibility is suggested by the fact that it is reported that only about $50 \%$ of the NDNS children aged 1.5-4.5 years consumed meat during the 4-day interview period, although no information is given on the percentage of vegetarian children 
included. However, the wider age groups may also be a factor. Twenty-three per cent of 8-month-old infants in $\mathrm{Avon}^{3}$ had $\mathrm{Hb}<110 \mathrm{gl}^{-1}$ compared with only $2.6 \%$ of the present 1 year olds but the Avon authors conclude that the cut-off point of $110 \mathrm{gl}^{-1}$ may be inappropriate for $\mathrm{Hb}$ estimated from capillary blood, which can become diluted with serum during the sampling procedure. $\mathrm{Hb}$ and red cell mass are gradually increasing at this point, and iron stores are being utilized to sustain the increases. This would explain the apparent contradictions found in Avon in relation to correlations with weight at age 8 months. Weight gain correlated positively with $\mathrm{Hb}$ but negatively with SF. As the infant grows the reserves of iron are mobilized to sustain the expansion in blood volume and red cell mass which is associated with growth ${ }^{16}$. A similar dynamic, associated with pubertal growth, has been shown in Finnish boys ${ }^{17}$.

Iron deficiency at age 12 months was strongly related to the early introduction of cows' milk. This finding is not surprising as the contribution of cows' milk to iron deficiency in infancy is well documented ${ }^{18,19}$. Milk intakes were recorded frequently during the first year of life and are deemed to be an accurate estimate of consumption. Age of introduction could be used in the regression model interchangeably with quantity of cows' milk to confirm the validity of the results. Furthermore, these data supply information about milk intakes during a period preceding blood sampling and should, therefore, give a more accurate picture of the influence of milk consumption on iron status. The recommendation to avoid cows' milk as the primary milk drink until age 12 months is now widely publicised. However, cows' milk has traditionally been used at an earlier age and, while the majority of mothers delayed its introduction until 9 months, by age 12 months cows' milk was commonly the main milk consumed. Cows' milk was more frequently used at an early age in the present sample, with $7 \%$ consuming cows' milk by age 6 months compared with $3 \%$ of those in the NDNS $^{2}$. However, approximately $27 \%$ of infants in both groups were reported to be drinking cows' milk by age 9 months.

Severe maternal anaemia during pregnancy was found to be present in the mothers of both infants who were anaemic at age 12 months. Although no postnatal blood samples were taken, it is known that severe maternal iron deficiency compromises the level of iron laid down by the fetus in utero, hastening the infant's dependence on dietary iron. A recent Danish study has shown significant tracking for SF between the ages of 2 and 9 months, suggesting a close relationship between postnatal iron status and iron status in later infancy ${ }^{20}$ and a number of studies have confirmed the relationship between maternal and infant ferritin levels, particularly when maternal iron stores are low ${ }^{21,22}$.
The most significant determinant of iron status at the ages of 24 and 36 months is earlier iron status, so it appears that the tracking effect seen in infancy continues into the second and third years and that determinants of early iron status continue to have an influence. The deterioration in iron status between the ages of 12 and 24 months is also due to the change from a fortified to an unfortified diet and a failure to replace the fortification iron with food iron. Iron intake in infants aged 9-12 months has been shown to be lower than in 6-9 month olds as a result of the decreased reliance on fortified foods ${ }^{23}$. In the present sample, diet is failing to provide sufficient iron to support erythropoesis in almost one in ten children at age 24 months. The improvement in the third year may be a reflection of the fact that the infants are reaching an equilibrium in terms of iron turnover. In early childhood, when there is a high demand for dietary iron but a relatively low energy intake, the provision of a nutrient dense diet is essential to meeting the nutritional needs of the child. Cereals were found to be the major energy provider in the NDNS, with biscuits, buns, cakes and pastries providing a greater proportion of the energy derived from cereal than either bread or breakfast cereals ${ }^{2}$. The excessive use of foods which do not provide essential nutrients increases the risk that deficiencies will develop. This is particularly true of iron deficiency. The demand for iron is high, absorption of iron is relatively poor, especially from foods containing non-heme iron, and heme iron, found only in meat, fish or chicken, is not widely dispersed in the diet.

A lower range $\left(5-12 \mu \mathrm{gl}^{-1}\right)$ for $\mathrm{SF}$ at age 12 months, was seen in the small number of breast fed infants in the present sample, but breast feeding should not be interpreted as a risk factor for iron deficiency anaemia. The extensive health benefits of breast feeding are well documented and no child who was breast fed became anaemic. Differences in iron storage levels in late infancy are likely to result from high intakes of supplemental iron by formula fed infants ${ }^{24}$ rather than from an inadequate supply of iron in the diets of those who are breast fed. As a result, the breast fed baby does not experience the dietary iron deficit which results from the change to an unfortified from a fortified milk and, given an adequate intake of iron from complementary foods, lower levels of storage iron stimulate increased absorption of iron, to maintain iron homoeostasis. Levels of breast feeding in Ireland are low, so a National Breastfeeding Policy has been designed to improve both the uptake and duration of breast feeding ${ }^{25}$. Higher levels of breast feeding have been reported in the UK and Scotland $2,23,26$ and should be a realistic objective in our similar population.

For the infant who is not breast fed, formula milk can 
provide a substantial proportion of the iron required during the first year of life and it is vital that the use of cows' milk as the main milk drink should continue to be discouraged. However, iron fortification of formula still presents some difficulties. The optimal level of fortification remains unclear ${ }^{27,28}$ and a recent study has shown that ascorbic acid supplementation of formula, designed to enhance iron absorption, causes the formation of free radicals in vitro ${ }^{29}$. In addition, there is some danger that over reliance on bottle feeding will prevent the initiation of weaning on to a good variety of solid foods. Mothers tend to discontinue the use of iron fortified formula towards the end of the first year when the resulting deficit in dietary iron should be met by the foods consumed. If an equivalent volume of cows' milk is substituted in place of formula it may provide adequate energy, but the requirement for other nutrients, including iron, will not be met.

Meat, fish and poultry, which are generally available in developed countries, contain the most bio-available form of iron, heme iron. Recent studies have confirmed that meat intake influences iron status in infants and young children ${ }^{20,30}$. A report on infant feeding 'Weaning and the Weaning Diet' recommends the inclusion of meat from the age $4-6$ months $^{31}$. This recommendation is of particular relevance given the significant increase in anaemia which is found in the second year of life. All infants and young children should be encouraged to eat a wide variety of nutrient dense foods, including meat, in the knowledge that they have a high requirement for iron. By tackling the problem from a dietary perspective, the development of good eating habits, which will continue to provide for the nutrient needs of the growing child, is encouraged. This, and not increasing reliance on greater fortification of formula, should be the cornerstone of the prevention of anaemia and iron deficiency of late infancy and childhood in the future.

\section{Acknowledgements}

We acknowledge the wonderful co-operation of all participating children and their parents and the financial support of Cow \& Gate Nutricia Ireland Ltd and of Nutriscan Ltd. Particular thanks to Mrs Bridie McNulty and Mrs Olga Brookes for help with blood sampling, to Mr Brian Kelleher and Mr Sean O'Broin who completed the analyses and to Dr Christoph Male. This study contributes in part to a longitudinal multicentre study, the Eurogrowth Study.

This work was carried out at the University of Dublin, Trinity College, Dublin, Ireland and statistical assistance was given by the Catholic University of Nijmegen, The Netherlands.

\section{References}

1 Oski FA. Iron deficiency in infancy and childhood. N. Engl.J. Med. 1993; 329: 190-3.

2 Gregory JR, Collins DL, Davies PSW, Hughes JM, Clarke PC. National Diet and Nutrition Survey: children aged 11/2-41/2 years. London: HMSO, 1995.

3 Emond AM, Hawkins N, Pennock C, Golding $\mathrm{J}$ and the ALSPAC Children in Focus Team. Haemoglobin and ferritin concentrations in infants at 8 months of age. Arch. Dis. Child. 1996; 74: 36-9.

4 Walter T, De Andraca I, Chadud P, Perales CG. Iron deficiency anaemia: adverse effects on infant psychomotor development. Pediatrics 1989; 84: 7-17.

5 Lozoff B, Jimenez E, Wolf AW. Long-term developmental outcome of infants with iron deficiency. N. Engl. J. Med. 1991; 352: 687-94.

6 Walter T. Impact of iron deficiency on cognition in infancy and childhood. Eur. J. Clin. Nutr. 1993; 47: 307-16.

7 Erhardt P. Iron deficiency in young Bradford children from different ethnic groups. Br. Med. J. 1986; 292: 90-3.

8 Kim SK, Cheong WS, Jun YH, Choi JW, Son BK. Red blood cell indices and iron status according to feeding practices in infants and young children. Acta Paediatr. 1996; 85: 139-44.

9 James J, Lawson P, Male P, Oakhill A. Preventing iron deficiency in pre-school children by implementing an educational and screening programme in an inner city practice. Br. Med. J. 1989; 299: 838-40.

10 Daly A, MacDonald A, Aukett A, Williams J, Wolf A, Davidson J, Booth IW. Prevention of anaemia in inner city toddlers by an iron supplemented cows' milk formula. Ancb. Dis. Child. 1996; 75: 9-16.

11 Duggan MB, Steel G, Elwys G, Harbottle L, Noble C. Iron status, energy intake, and nutritional status of healthy young Asian children. Arch. Dis. Cbild. 1991; 66: 1386-9.

12 Mills AF. Surveillance for anaemia: risk factors in patterns of milk intake. Arch. Dis. Child. 1990; 65; 428-31.

13 Jacobs A, Worwood M. Ferritin in serum. N. Engl. J. Med. 1975; May: 951-6.

14 Burman D. Haemoglobin levels in normal infants aged 3 to 24 months, and the effect of iron. Arch. Dis. Child. 1972; 47 : 261-71.

15 Dallman P, Yip R, Johnson C. Prevalence and causes of anemia in the United States, 1976 to 1980 . Am. J. Clin. Nutr. 1984; 39: 437-45.

16 Burman D. Iron metabolism in infancy and childhood. In: Jacobs $\mathrm{A}$, Worwood $\mathrm{M}$, eds. Iron in Biocbemistry and Medicine. London and New York: Academic Press, 1974; 543-62.

17 Antrila R, Siimes MA. Serum transferrin and ferritin in pubertal boys: relations to body growth, pubertal stage, erythropoiesis and iron deficiency. Am. J. Clin. Nutr. 1996; 63: 179-83.

18 Penrod JC, Anderson K, Acosta, PB. Impact on iron status of introducing cows' milk in the second six months of life. $J$. Paediatr. Gastro. \& Nutr. 1990; 10: 462-7.

19 Harbottle L, Duggan MB. Comparative study of the dietary characteristics of Asian toddlers with iron deficiency in Sheffield. J. Hum. Nutr. Diet. 1992; 5: 351-61.

20 Michaelsen KF, Milman N, Samuelson G. A longitudinal study of iron status in healthy Danish infants: effects of early iron status, growth velocity and dietary factors. Acta Paediatr. 1995; 84: 1035-44.

21 Puolakka J, Jänne $O$, Vihko R. Evaluation by serum ferritin assay of the influence of maternal iron stores on the iron status of newborns and infants. Acta Obstet. Gymecol. Scand. Suppl. 1980; 95: 53-6.

22 Kelly AM, Macdonald DJ, McDougall AN. Observations on maternal and fetal ferritin concentrations at term. Br.J. Obst. E Gynae. 1978; 85: 338-43. 
23 Mills A, Tyler H. Food and Nutrient Intakes of British Infants Aged 6-12 Months. London: HMSO, 1992.

24 Schulz-Lell G, Buss R, Oldigs H-D, Dörner K, Schaub J. Iron balances in infant nutrition. Acta Paediatr. Scand. 1987; 76: 585-91.

25 Health Promotion Unit. A National Breastfeeding Policy for Ireland. Dublin: Health Promotion Unit, Department of Health, 1994.

26 Ferguson AE, Tappin DM, Girwood RWA, Kennedy R, Cockburn F. Breast feeding in Scotland. Br. Med. J. 1994; 308: 824-5.

27 Bradley CK, Hillman L, Sherman AR, Leedy D, Cordano A. Evaluation of two iron-fortified, milk-based formulas during infancy. Pediatrics 1993; 91: 908-14

28 Fomon SJ, Ziegler EE, Serfass RE, Nelson SE, Frantz, JA.
Erythrocyte incorporation of iron is similar in infants fed formulas fortified with $12 \mathrm{mg} / 1$ or $8 \mathrm{mg} / \mathrm{l}$ of iron. $J$. Nutr. 1997; 127 (1): 83-8.

29 Almaas R, Rootwelt T, Oyasaeter S, Saugstad OD. Ascorbic acid enhances hydroxyl radical formation in iron-fortified infant cereals and infant formulas. Eur. J. Pediatr. 1997; 156 488-92.

30 Mira M, Alperstein G, Karr M, Ranmuthugala G, Causer J, Niec, A, Lilburne A-M. Haem iron intake in 12-36 month children depleted in iron: case-control study. Br. Med. J. 1996; 312: 881-3.

31 Department of Health. Report on Health and Social Subjects no. 45. Weaning and the Weaning Diet. London: HMSO, 1994. 